\title{
Optimizing Customer Satisfaction by Using Kano's Model for Eco-efficiency and Green Design
}

\author{
Lara F. Hourani \\ Department of Management Science and Engineering, Northwestern Polytechnical University, Xi'an, China
}

\section{Email address:}

Larahurani@yahoo.com

\section{To cite this article:}

Lara F. Hourani. Optimizing Customer Satisfaction by Using Kano's Model for Eco-efficiency and Green Design. Journal of Investment and Management. Vol. 4, No. 5, 2015, pp. 285-290. doi: 10.11648/j.jim.20150405.30

\begin{abstract}
This paper presents Kano model to measure customer satisfaction for the eco-efficiency and green design. This method can be used to support the designer for reducing the environmental impact of the product throughout its life cycle and as a supporting tool for designers to invent novel, useful, and environmentally friendly products, our approach is to develop this method by linking concepts from marketing and environments to show the competitive advantage of creating a high level of customer satisfaction by adopting the requirements of the eco-efficiency and green design. For that I will begins with a brief discussion for the eco-efficiency and green design then identify the requirements of the eco-efficiency and green design and lastly propose Kano model to measure customer satisfaction for the eco-efficiency and green design. Kano's model of customer satisfaction, a methodology is introduced which determines which influence the components of products and services have on customer satisfaction. And also demonstrate how the results of a customer survey can be interpreted and how conclusions can be drawn and used to demonstrate the customer satisfaction for eco-efficiency and green design. As we see the result of the study shows that the eco-efficiency and green design for the goods and services have a competitive advantage.
\end{abstract}

Keywords: Green Design, Eco-efficiency Design, Customer Satisfaction, Kano's Model

\section{Introduction}

The major concern and Essential condition for competitiveness global market recently is Customer satisfaction. Because of market evenness in product quality, the subjective quality of aesthetics is a critical determinant of customer satisfaction [14] [5].

The concept of eco-efficiency and green design heading the environmental issue through design process which is objecting to the traditional design approach, in response to the growing public concern in protecting the environment, numerous firms have been actively involving in designing and promoting green design products and services [13]. Eco-efficiency and Green design has arisen as a creative and sustainable tool for solving the environmental problems. There are many strategies mentioned in the literature and used virtually can be used practically in design and manufacturing by to improve the sustainability of their products and services. These strategies include Waste Minimization, Resource Efficiency, Resource Productivity, Eco-efficiency, Pollution Prevention and many more [7]. Although there have been different views to support eco-efficiency and green design and, most of the results echo the objective of design for environment or design for end of life [15].

Managers need a set of practical step-by-step tools and methods which ensure a better understanding of customers' requirements, to promote communication by concentrating on the voice of the customer within a product and services. To meet customer expectations and increase customer satisfaction.

To evaluate customer satisfaction Kano method are applied. The Kano method was developed in the 1980 s to facilitate design of innovative products its suitable for determining the coherences between customer requirements, product characteristics and customer satisfaction, its used to better understand the relationship between performance criteria and customer satisfaction. By a special Kano interview, which is based on a combined functional and dysfunctional questionnaire, basic factors, satisfiers and exciters can be identified. These factors are used do determine the customer requirement's importance for the customer satisfaction [1] [12] [5].

And at the end the study will try to answer these questions: Does the eco-efficiency and green design create a competitive advantage for the goods and services? 
Which new requirements would better meet the expectations of the customer?

What would the customer change in the product and services?

This question is used to identify those new requirements and expectations which the customer is aware of, but which have not yet been fulfilled by the current product range, such as being able to reduce the energy intensity of the goods and services for a new model, or reduce the dispersion of any toxic materials.

To achieve the aim of this paper which is proposing a method that can measure the customer satisfaction for the eco-efficiency and green design. For that I will begins with a brief discussion for the eco-efficiency and green design then identify the requirements of the eco-efficiency and green design and lastly propose Kano model to measure customer satisfaction for the eco-efficiency and green design.

\subsection{Green Design and Eco-efficiency}

The development of technology has important impact in modern economic growth, but it also the key factor of environmental crisis. It usually emphasizes the novelty and economic usefulness but neglects its environmental impact [11] [3].

Green design intends to conceive of products and services that meet the needs of society while striking a balance between economic and environmental interests. The term green design was the first to be used by the design community as they became aware of environmental considerations in the early 1990s, The most widely known definition of green design is using renewable sources of energy and use recycling (renewable/toxic-free/biodegradables) and. Resources and which improves environmental impact or reduces environmental toxic damage throughout its entire life cycle [10].

Eco efficiency is reached by the delivery of competitive priced goods and services that satisfy human needs and bring quality of life, while progressively reducing ecological impacts and resource intensity throughout the life cycle to a level at least in line with the earth's estimated carrying capacity according to the ISO 14000 definition of environmental performance and impact.

The concept of eco-efficiency is based on creating more goods and services while using fewer resources and creating less waste and pollution. The efficiency can be a good starting point when thinking about green design. Designers can look for opportunities to reduce material and energy used throughout the life cycle of a product. By doing so, it is possible to not only reduce the environmental impact of a design, but also to reduce costs. This can be a particularly persuasive selling point for skeptical clients or management [2].

\subsection{Green Design and Eco-efficiency Requirements}

The seven major requirements has pointed out by WBCSD in considering the eco-efficiency of environmental friendly products to reduce environmental impacts [6].

A. Reduce the material intensity of its goods and services
B. Reduce the energy intensity of its goods and services

C. Reduce the dispersion of any toxic materials

D. Enhance the recyclability of its materials

E. Maximize the sustainable use of renewable resources

F. Extend the durability of its products

G. Increase the service intensity of its goods and service.

\subsection{Kano's Model of Customer Satisfaction}

In Kano model [8]. To motivate designers and decision makers to incorporate green design and eco-efficiency requirements, such as amount of material, degree of recyclability, amount of energy consumption during use, and ease of disassembly, into their products and services, the value of the design to the organization must be established. Kano's model can be used to clarify customers' perceptions of s green design requirements. A single person encountering a green design may feel satisfied, dissatisfied, or indifferent with that design. Kano's model categorizes a single customer's perceptions of a design as one of five mutually exclusive types: "one-dimensional," "must-be," "attractive," "indifferent," or "reverse." These definitions are based on three feelings: the feeling (satisfied, indifferent, or dissatisfied).

\subsection{1. 'Must-Be' Requirements}

A customer views the requirements as must-be and basic criteria of the product or service. If this requirement is absent the customer will be extremely dissatisfied. On the other hand, as the customer takes these requirements for granted, if the requirement is present, it will not increase the satisfaction and feels indifferent or has no feeling for it.

Present of the must-be requirements will only lead to a state of 'not dissatisfied'. Requirements related to health and safeties are usually perceived as must-be because people expect most products to be safe. So they have no feelings when the product or service is safe, but normally have strong feelings of dissatisfaction when a product is not safe.

\subsubsection{One-Dimensional Requirements}

According to Kano's definition [9], the customers realize requirements as one-dimensional if they feel satisfied when the requirement is present in the design of the product or service and feels dissatisfied when the requirement is absent. With regard to these requirements, customer satisfaction increases as much as the requirement is fulfill - the higher the level of fulfillment, the higher the customer's satisfaction. One-dimensional requirements are usually explicitly demanded by the customer.

\subsubsection{Attractive Requirements}

Attractive requirements is considered attractive to a customer if they feel satisfied when the requirement is present but have no feeling when the requirement is absent. It has the most significant influence on how the satisfaction of the customer will be with a given design.

Attractive requirements are not expected by the customer. Meeting these requirements leads to more than proportional satisfaction. And if they are not present, there is no feeling of dissatisfaction. 


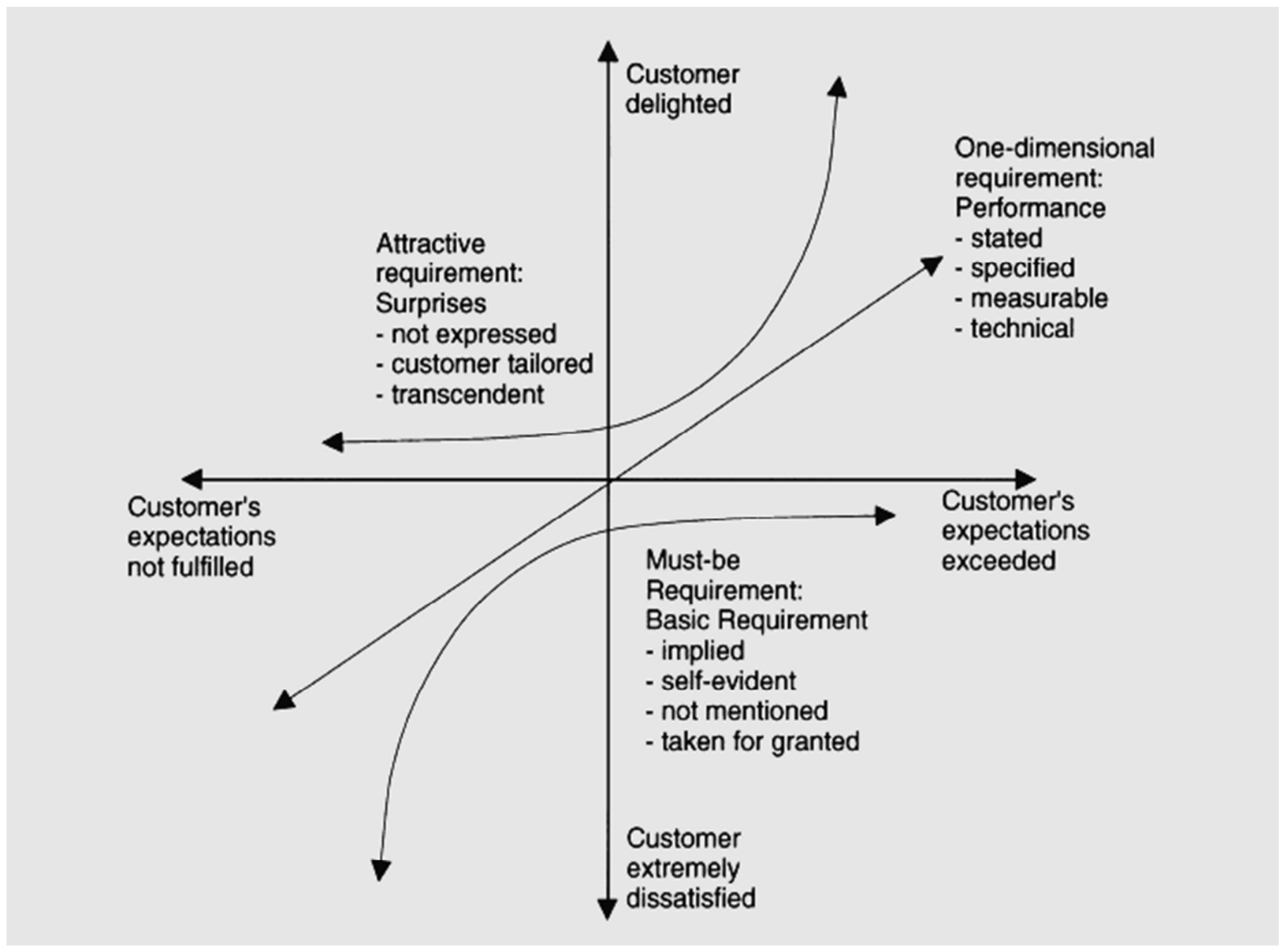

Figure 1. Kano's model of customer satisfaction [4].

\subsubsection{Indifferent Requirements}

An indifferent requirement creates no feeling for the customer when it is present and no feeling when it is absent. May be its no need to design indifferent requirements, as they give no perceived value to customers and yet bear costs to design, produce, and distribute. Not all indifferent requirements are useless, however. Sometimes for the customers the requirements are indifferent when they do not understand the value of it.

\subsubsection{Reverse Requirements}

The requirement is considered reverse if the customer feels a satisfied when the requirement is absent or feels dissatisfied when the requirement is present. Reverse requirements might support costs related to sales, design, materials, production, or distribution while decreasing the value of the product by creating dissatisfaction or removing satisfaction.

\section{A Methodology to Evaluate Customer Requirements}

\section{Data collection}

The questionnaire of the Kano model involves design of a survey that categorizes each customer's perceptions into the five Kano categories: Must-be, one-dimensional, attractive requirements, indifferent and reverse.

Table 1. Kano's questionnaire for one of the Green design and eco-efficiency requirements.

\begin{tabular}{|c|c|}
\hline Question & Passible answers \\
\hline $\begin{array}{l}\text { Q1. How do you feel about the } \\
\text { reduction of the material } \\
\text { intensity of the goods and } \\
\text { services }\end{array}$ & $\begin{array}{l}\text { 1. I like it } \\
\text { 2. I expect it to be that way } \\
\text { 3. I do not feel anything } \\
\text { 4. There is no other choice } \\
\text { 5. I do not like it } \\
\text { 1. I like it } \\
\text { 2. I expect it to be that way } \\
\text { 3. I do not feel anything } \\
\text { 4. There is no other choice } \\
\text { 5. I do not like it }\end{array}$ \\
\hline
\end{tabular}

For The Kano survey, 200 questionnaires distributed to ranked random sample, the survey examine the Green design and eco-efficiency requirements, Must-be, one-dimensional and attractive requirements as well as products and services requirements towards which the customer is indifferent can be classified by means of a questionnaire. For each Green design and eco-efficiency requirement a pair of multiple-choice questions is formulated to which the 
customer can answer in one of five different ways for every question [8]. The first question concerns the reaction of the customer felling if the product has the Green design and eco-efficiency requirement (functional form of the question), and the second question concerns the customer's feeling when the requirement is absent (dysfunctional form of the question).

\section{Survey Analysis}

Table 2 explain how the answers to the questions in table 1 , are used to classify one customer's perception of the Green design and eco-efficiency requirements into the Kano categories Hence, if a customer answers "1. I like it" to question 1 (Q1) and "2. I expect it to be that way" to question 2 (Q2), that customer perceives the "absence of reduction of the material intensity of the goods and services" in the product or the services. If another customer answers " 2 . I expect it to be that way" to Q1 and "5. I don't like it" to Q2, that customer perceives the "absence of Reduction of the material intensity of the goods and services" as a must-be of the Green design and eco-efficiency requirements.

Table 2. Functional and dysfunctional questions for the single Green design and eco-efficiency requirement.

\begin{tabular}{|c|c|c|c|c|c|c|}
\hline & & \multicolumn{5}{|c|}{ dysfunctional form of the question } \\
\hline & & I like it & $\begin{array}{c}\text { I expect it to be } \\
\text { that way }\end{array}$ & $\begin{array}{c}\text { I do not feel } \\
\text { anything }\end{array}$ & $\begin{array}{c}\text { There is no other } \\
\text { choice }\end{array}$ & $\begin{array}{c}\text { I do not } \\
\text { like it }\end{array}$ \\
\hline \multirow{5}{*}{$\begin{array}{l}\text { Functional form of the } \\
\text { question }\end{array}$} & I like it & Q & A & A & A & $\mathrm{O}$ \\
\hline & I expect it to be that way & $\mathrm{R}$ & I & I & I & M \\
\hline & I do not feel anything & $\mathrm{R}$ & I & I & I & M \\
\hline & There is no other choice & $\mathrm{R}$ & I & I & I & M \\
\hline & I do not like it & $\mathrm{R}$ & $\mathrm{R}$ & $\mathrm{R}$ & $\mathrm{R}$ & Q \\
\hline
\end{tabular}

Key to customer's perception: A: attractive I: indifferent O: one-dimensional R: reverse M: must-be Q: questionable The next step is to assemble the multiple customer perceptions for each requirement. Every cell in table 3 indicates the percentage of Surveyed who supplied that combination of answers for that requirement. Thus, table 3 provides the means to determine a market division's perspective of a requirement.

Table 3. The perception of one of the Green design and eco-efficiency requirements" Reduce the material intensity of its goods and services".

\begin{tabular}{|c|c|c|c|c|c|c|}
\hline & & \multicolumn{5}{|c|}{ dysfunctional form of the question } \\
\hline & & I like it & $\begin{array}{l}\text { I expect it to be } \\
\text { that way }\end{array}$ & $\begin{array}{l}\text { I do not feel } \\
\text { anything }\end{array}$ & $\begin{array}{l}\text { There is no other } \\
\text { choice }\end{array}$ & $\begin{array}{c}\text { I do not } \\
\text { like it }\end{array}$ \\
\hline \multirow{3}{*}{$\begin{array}{l}\text { Functional form of the } \\
\text { question }\end{array}$} & I expect it to be that way & $0 \%$ & $0 \%$ & $5 \%$ & $5 \%$ & $5 \%$ \\
\hline & I do not feel anything & $0 \%$ & $5 \%$ & $15 \%$ & $5 \%$ & $0 \%$ \\
\hline & I do not like it & $0 \%$ & $0 \%$ & $0 \%$ & $0 \%$ & $0 \%$ \\
\hline
\end{tabular}

For example, tables 2 and 3 indicate that $20 \%(5 \%+15 \%$ $+0 \%$ ) of Green design requirement viewed the absence of Reduction of the material intensity of its goods and services requirement, $40 \%$ perceived it as one-dimensional, $5 \%$ saw it as must-be, $35 \% \quad(0 \%+5 \%+5 \%+5 \%+15 \%+5 \%)$ were indifferent, and $0 \%$ viewed the absence of Reduce the material intensity of its goods and services requirement.

Table 4 demonstrates that $40 \%$ viewed satisfaction and dissatisfaction with absence of reduction of the material intensity of its goods and services requirement in opposites (the One- dimensional view), and only 5\% viewed dissatisfaction with absence of reduction of the material intensity of its goods and services requirement (the must be view), and $20 \%$ viewed satisfaction with present of reduction of the material intensity of its goods and services requirement and no feeling in opposites (the Attractive view).
Table 4 summarizes the perception of all the Green design and eco-efficiency requirements Analysis such as that exhibited in table 4 helps designers discover the Green design and eco-efficiency requirements that fit best with the current designs, projects, marketing, and sales strategy. For example, the absence of Reduction of the dispersion of any toxic materials was must-be and so could not be neglected, even though essential effort was required to insert alternatives into the design to remove items such as Increasing the service intensity of its goods and service, because the absence of it was viewed with indifference, knowledge transfer through sales stuff and advertising promotions was initiated the Reduction of the energy intensity of its goods and services, however, was viewed as attractive and was used to promote and sell the product and services of the Green design and eco-efficiency. 
Table 4. The perception of all the Green design and eco-efficiency requirements.

\begin{tabular}{|c|c|c|c|c|c|c|c|c|}
\hline Green design, eco-efficiency requirements & $\mathbf{A}$ & $\mathbf{O}$ & $\mathbf{M}$ & $\mathbf{I}$ & $\mathbf{R}$ & $\mathbf{Q}$ & Total & Category \\
\hline Reduce the material intensity of its goods and services & $20 \%$ & $40 \%$ & $5 \%$ & $35 \%$ & $0 \%$ & $0 \%$ & $100 \%$ & $\mathrm{O}$ \\
\hline Reduce the energy intensity of its goods and services & $30 \%$ & $25 \%$ & $15 \%$ & $20 \%$ & $0 \%$ & $10 \%$ & $100 \%$ & A \\
\hline Reduce the dispersion of any toxic materials & $15 \%$ & $25 \%$ & $40 \%$ & $20 \%$ & $0 \%$ & $0 \%$ & $100 \%$ & M \\
\hline Enhance the recyclability of its materials & $20 \%$ & $40 \%$ & $20 \%$ & $15 \%$ & $5 \%$ & $0 \%$ & $100 \%$ & $\mathrm{O}$ \\
\hline Maximize the sustainable use of renewable resources & $20 \%$ & $25 \%$ & $35 \%$ & $15 \%$ & $5 \%$ & $0 \%$ & $100 \%$ & M \\
\hline Extend the durability of its products & $20 \%$ & $40 \%$ & $5 \%$ & $35 \%$ & $0 \%$ & $0 \%$ & $100 \%$ & $\mathrm{O}$ \\
\hline Increase the service intensity of its goods and service & $30 \%$ & $20 \%$ & $15 \%$ & $20 \%$ & $5 \%$ & $10 \%$ & $100 \%$ & A \\
\hline
\end{tabular}

Table 5. The perception of the customer satisfaction coefficient for all the Green design and eco-efficiency requirements.

\begin{tabular}{|c|c|c|c|c|c|c|c|c|c|c|}
\hline $\begin{array}{l}\text { Green design, eco-efficiency } \\
\text { requirements }\end{array}$ & $\mathbf{A}$ & $\mathbf{O}$ & M & $\mathbf{I}$ & $\mathbf{R}$ & $\mathbf{Q}$ & Total & Category & $\frac{\mathbf{A}+\mathbf{0}}{\mathbf{A}+\mathbf{O}+\mathbf{M}+\mathbf{I}}$ & $\frac{\mathbf{0 + M}}{(\mathbf{A}+\mathbf{0}+\mathbf{M}+\mathbf{I})(-1)}$ \\
\hline $\begin{array}{l}\text { Reduce the material intensity of its } \\
\text { goods and services }\end{array}$ & $20 \%$ & $40 \%$ & $5 \%$ & $35 \%$ & $0 \%$ & $0 \%$ & $100 \%$ & $\mathrm{O}$ & 0.60 & -0.45 \\
\hline $\begin{array}{l}\text { Reduce the energy intensity of its } \\
\text { goods and services }\end{array}$ & $30 \%$ & $25 \%$ & $15 \%$ & $20 \%$ & $0 \%$ & $10 \%$ & $100 \%$ & A & 0.61 & -0.44 \\
\hline $\begin{array}{l}\text { Reduce the dispersion of any toxic } \\
\text { materials }\end{array}$ & $15 \%$ & $25 \%$ & $40 \%$ & $20 \%$ & $0 \%$ & $0 \%$ & $100 \%$ & M & 0.40 & -0.65 \\
\hline $\begin{array}{l}\text { Enhance the recyclability of its } \\
\text { materials }\end{array}$ & $20 \%$ & $40 \%$ & $20 \%$ & $15 \%$ & $5 \%$ & $0 \%$ & $100 \%$ & $\mathrm{O}$ & 0.63 & -0.63 \\
\hline $\begin{array}{l}\text { Maximize the sustainable use of } \\
\text { renewable resources }\end{array}$ & $20 \%$ & $25 \%$ & $35 \%$ & $15 \%$ & $5 \%$ & $0 \%$ & $100 \%$ & M & 0.58 & -0.63 \\
\hline Extend the durability of its products & $20 \%$ & $40 \%$ & $5 \%$ & $30 \%$ & $0 \%$ & $5 \%$ & $100 \%$ & $\mathrm{O}$ & 0.63 & -0.47 \\
\hline $\begin{array}{l}\text { Increase the service intensity of its } \\
\text { goods and service }\end{array}$ & $30 \%$ & $20 \%$ & $15 \%$ & $20 \%$ & $5 \%$ & $10 \%$ & $100 \%$ & A & 0.55 & -0.41 \\
\hline
\end{tabular}

\section{Customer satisfaction coefficient}

The customer satisfaction coefficient states whether satisfaction can be increased by meeting a product - services requirement, or whether accomplishing this product requirement simply prevents the customer from being dissatisfied [4].

The customer satisfaction coefficient is indicative of how strongly the design may influence satisfaction or, in the case of its nonfulfillment, customer dissatisfaction. To calculate the average impact on satisfaction it is necessary to add the attractive and one-dimensional columns and divide by the total number of attractive, one-dimensional, must-be and indifferent responses. For the calculation of the average impact on dissatisfaction, add the must-be and one-dimensional columns and divide by the same normalizing factor [4].

Extent of satisfaction:

$$
\frac{A+O}{(A+O+M+I)}
$$

Extent of dissatisfaction:

$$
\frac{\mathrm{O}+\mathrm{M}}{(\mathrm{A}+\mathrm{O}+\mathrm{M}+\mathrm{I}) *(-1)}
$$

A minus sign is put in front of the customer satisfaction coefficient of customer dissatisfaction in order to emphasize its negative influence on customer satisfaction if this design not fulfilled. The positive customer satisfaction coefficient ranges from 0 to 1 ; the closer the value is to 1 , the higher the influence on customer satisfaction. A positive customer satisfaction coefficient which approaches 0 signifies that there is very little influence. At the same time, however, one must also take the negative customer satisfaction coefficient into consideration. If it approaches -1 , the influence on customer dissatisfaction is especially strong if the analyzed requirement is not fulfilled. A value of about 0 signifies that this requirement does not cause dissatisfaction if it is not met.

For example, no Reducing for the dispersion of any toxic materials with a negative customer satisfaction coefficient of -0.65 leads to more than proportional dissatisfaction to Reduce the dispersion of any toxic materials with a positive customer satisfaction coefficient of 0.40 can only slightly increase satisfaction (see Table 4 ).

\section{Conclusion and Discussion}

This paper propose Kano's model of customer satisfaction for eco-efficiency and green design show that it can be used to make obvious customer understanding for eco-efficiency and green design. Because the customers become more aware of the need for eco-efficiency and green design to solve the environments problems, the results shows that there is increasing in the influence of the eco-efficiency and green design and shows relative significance of this requirements and its estimation from the customer's viewpoint in the product and service design, the satisfaction can be suitable tools can be used.

The long-term objective is to develop customer satisfaction with regard to significant eco-efficiency and green design requirements in order to establish sustainable competitive advantages, and integrate the environmental requirements throughout the entire lifetime of the services and product design. Which influence the customer satisfaction and give the design a competitive advantage, for that the (must-be, one-dimensional or attractive requirement) should be fulfilled. 
The result in the study shows that the must-be requirements are Reducing the dispersion of any toxic materials and Maximize the sustainable use of renewable resources which customer take it for granted, if these requirements are not fulfilled the customer will be dissatisfied, and the customer will not be interested in the product at all. Because they are basic criteria the absent of Reducing the dispersion of any toxic materials lead to dissatisfaction with a negative customer satisfaction coefficient of -0.65 as it shown in table (4) which is the highest average of dissatisfaction if the requirements are absent. And the one-dimensional requirements for the eco-efficiency and green design are: Reduce the material intensity of its goods and services, Enhance the recyclability of its materials and Extend the durability of its products, and the present of this requirements give significant competitive advantage to the product or service design, with positive customer satisfaction coefficient $(0.60),(0.63),(0.63)$ reflect the satisfaction for fulfilling this requirements. With regard to these requirements, customer satisfaction is proportional to the level of fulfillment - the higher the level of fulfillment, the higher the customer's satisfaction. The attractive requirements which have the greatest influence on how satisfied a customer will be with reducing the energy intensity of its goods and services, increasing the service intensity of its goods and service. Fulfilling these requirements leads to positive customer satisfaction coefficient $(0.61),(0.55)$ as it shown in the study. The result shows that all the eco-efficiency and green design requirements are (must-be, one-dimensional or attractive requirement) which mean that all this requirements have a competitive advantage for the goods and services and meet the expectations of the customer fulfilling these requirements increasing the customer satisfaction.

In this way product development projects can be managed more systematically the benefits are considerable.

\section{References}

[1] Abramovici, Ruhr 2007. Optimizing Customer Satisfaction by Integrating the Customer's Voice into Product Development.
[2] Anne Chick, Paul Sa 2011. Design for Sustainable Change: How Design and Designers Can Drive the Sustainability. Agenda / P.108

[3] Behrendt, S., Jasch, C., Peneda, M.C., and Van Weenen, H. (Eds.), 1997. Life Cycle Design, Springer-Verlag.

[4] Berger, C. et al 1993. Kano's methods for understanding customer-defined quality, Center for Quality Management Journal (Fall), 3-35.

[5] Chen, Chuang 2008. Integrating the Kano model into a robust design approach to enhance customer satisfaction with product design

[6] Chen, Liu 2003. An Eco-innovative Design Method by Green QFD and TRIZ Tools

[7] C.L. Chen 2001. Design for the environment: a quality-based model for green product development, Management Science.

[8] Kano, N. et al. 1984. Attractive quality and must-be quality. Hinshitsu: The Journal of the Japanese Society for Quality Control (April), 39-48.

[9] Kano, N., N. Seraku, F. Takahashi, and S. Tsuji. 1996. Attractive quality and must-be quality, in The best on quality, edited by J. D. Hromi. Milwaukee, WI: Quality Press

[10] Fabien Durif, Caroline Boivin, Charles Julien 2010. In search of a green product definition.

[11] Fiksel, J., "Design for Environment", McGraw-Hill, New York, 1996.

[12] Finster, Eagan, Hussey 2002. Linking Industrial Ecology with Business Strategy Creating Value for Green Product Design.

[13] Liua, Jib, Jiaoa 2013. A Stackelberg Solution to Joint Optimization Problems: A Case Study of Green Design

[14] Postrel, V. 2001. Can good looks guarantee a product's success? The New York Times July 12.

[15] S.H. Abdul Rashid 2009. An investigation into the material efficiency practices of UK manufacturers, Ph.D. Dissertation, Cranfield University. 